\title{
FACTORS CONTRIBUTING TOWARDS HIGH WATER USAGE WITHIN POOR COMMUNITIES IN KWAZULU-NATAL, SOUTH AFRICA
}

\author{
ROOKMONEY THAKUR ${ }^{1 *}$, GEOFFREY HARRIS ${ }^{1}$, SURENDRA THAKUR $^{2} \&$ STANLEY ONWUBU $^{3 \dagger}$ \\ ${ }^{1}$ Department of Public Management and Economics, Durban University of Technology, South Africa \\ ${ }^{2}$ Enterprise Development Unit, Durban University of Technology, South Africa \\ ${ }^{3}$ Dental Sciences, Durban University of Technology, South Africa
}

\begin{abstract}
Government bodies tasked with water resource management in recent years have by default placed more emphasis on increasing the water supply rather than reducing water demand. South Africa, however, is a semi-arid country plagued by unpredictable rainfall and severe drought conditions. The water authority bodies, usually operated by the municipalities, face high water losses due to aged inffastructure. This is exacerbated by a high daily water consumption amongst indigent residents, which is about $286 \mathrm{~L}$ per person compared to the international norm of $173 \mathrm{~L}$ per person. These two factors combine and contribute towards significant economic losses. The aim of this paper is to examine factors contributing towards high water consumption in poorer communities in Kwa-Zulu Natal, South Africa. The location of the study was a low-cost housing zone comprising a population of 20,000 people. A qualitative approach in a form of semi-structured interviews with main stakeholders from government, community-based organisations and academics was used to gather data. Three themes emerged from the study: (1) the viability of the current water management system; (2) reducing water consumption; and (3) how to change consumer behaviour towards water conservation. Results showed that the current water management system for the area was feasible and affordable. In addition, reducing water usage was possible through community involvement and communication. It was further noted that consumer behaviour can change through education concerning pricing and incentives.

Keywords: water sustainability, water management, water behaviour, indigent communities, education, community engagement, South Africa.
\end{abstract}

\section{INTRODUCTION}

Despite the change from an apartheid to a democratic form of government in 1994, water resources still remained unevenly distributed across South Africa [1]. As a matter of fact in the wake of the political transition water was seen as a bio-political tool aimed at transforming the lives of previously disadvantaged South Africans [2]. At that time approximately 13 million South Africans lacked access to safe water [3]. As part of the government's effort to fundamentally restructure its water laws and regulations, new legislations were introduced which represented water as an instrument in the transformation of society towards social and environmental justice [4]. The new water policies described water as a "public right" and "economic good". Significantly, it identified cost recovery as an integral measure towards building sustainable water services [5].

In addition, to fulfil the constitutional right to water, the government introduced a free basic water policy which meant that indigent households throughout South Africa would receive a stipulated amount of free water every month [6]. A "basic" supply means $25 \mathrm{~L}$ of water per person per day, easily accessible within a distance of $200 \mathrm{~m}$ of their household, regardless of the person's ability to pay for it. Accordingly, in July 2001, the Free Basic

\footnotetext{
* ORCID: http://orcid.org/0000-0003-0102-3151

† ORCID: http://orcid.org/0000-0002-4499-1534
} 
Water (FBW) policy became a national policy through a revised tariff structure that included at least $6 \mathrm{~m}^{3}$ of free water per month (i.e. $40 \mathrm{~L} /$ capita/day for a family of five or $25 \mathrm{~L} /$ capita/day for a family of eight) [7]. Subsequently, government gradually implemented the policy within each designated metropolitan municipality's jurisdiction and increased the amount to $9 \mathrm{~m}^{3}$ per family per month. However, South Africans have a relatively high per capita water use, around $286 \mathrm{~L}$ per person per day [8]. This is high in comparison to the international average of $173 \mathrm{~L}$ per person per day.

According to a study on household consumption in SA, many South African households used much more than $9 \mathrm{~m}^{3}$ per month [9]. The results of the above study showed that the average South African suburban family of four uses $300 \mathrm{~L}$ per person per day.

This equates to Fig. 1.

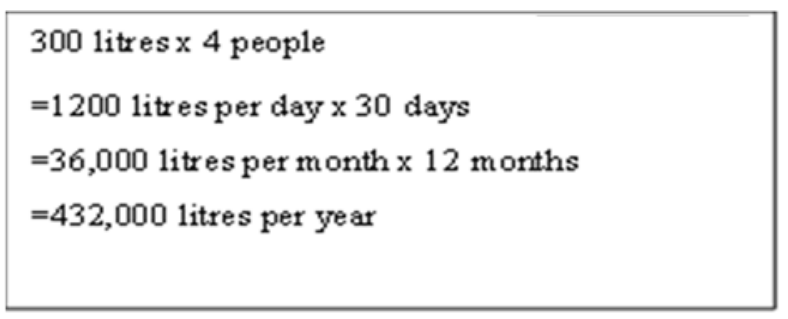

Figure 1: Annual average household consumption of a South African family of four [9].

These estimates suggest that the average South African uses at least four times more water than what is stipulated in the FBW. Despite the commendable efforts by government to improve water supply for impoverished and poorer communities, the study further highlighted that many municipalities tasked with water management lacked the administrative and technical capability to implement such water policies.

Water availability and sustainable usage is one of the key challenges of transforming the water sector and demand management in SA [10]. Over the years, the ministry in charge of water allocation, the South African Department of Water Affairs and Forestry (SADWAF) has faced challenges in calculating the amount of water people use per month in rural areas and low-cost housing areas due to poor infrastructure and lack of proper metering devices [11]. In this paper, low-cost housing areas refers to the government's program to provide houses to the poorest people living mainly in informal settlements. The criteria used to qualify for low-cost housing includes a disposable income per month of between $\$ 0-\$ 100$. Recipients of low-cost houses are provided with a certain amount of free electricity and $9 \mathrm{~m}^{3}$ of free water [12]. However, the latter has turned out to be problematic for water authorities as it has become a challenge to persuade residents to pay for water above the $9 \mathrm{~m}^{3}$ usage. Firstly, water authorities are unable to determine when water-users went beyond the stipulated $9 \mathrm{~m}^{3}$ a month [13]. Secondly, there is a culture of non-payment of services and dissatisfaction of some residents with water demand management strategies which further intensifies poor water behaviour [14]. This attitude can be attributed to the legacy of apartheid where the boycott of payment for services was an effective tool against the government [12].

It has often been argued that due to the scarcity of water resources government should not be providing it for free but put a price on its availability [13]. On the other hand, the initiative of using price as a demand management measure could give rise to more challenges facing municipalities [15]. In addition to civil protest action, communities unable to afford water will be susceptible to poverty and water-borne diseases [16]. This study takes cognisance of 
this and seeks to gain insight on factors contributing to high water consumption by inhabitants of low-cost housing areas in SA.

Water resources in SA which remains intricately interweaved with land resources, is vital to the continued economic development of cities and rural communities and towards the sustainable livelihoods of its people [17]. Not only are municipalities faced with high water losses due to aged infrastructure, it is also the high water consumption rates that contribute towards significant economic losses [18]. Worryingly, many of the communities based within the municipalities in SA are made up of impoverished people, which renders them particularly vulnerable to impacts of climate change and heavily dependent upon the services obtained from intact ecosystems [19].

The aim of this paper was to explore some of the factors contributing towards high water usage amongst inhabitants of poorer communities in Kwa-Zulu Natal, South Africa. This research explored how key behavioural factors influenced household water use. The location of the study is a low-cost housing area, known as Waterloo Township, situated in KwaZulu-Natal, South Africa with a population of 20,000 with the majority being of Black origin. Established in 1996, it is one of the oldest low-cost housing areas formed as part of the new government's Reconstruction of Development Plan (RDP). This plan was aimed to rebuild and develop the country which included meeting the basic needs such as jobs, housing, water and electricity and transport. Inhabitants here are recipients of FBW, which means that they are entitled to $9 \mathrm{~m}^{3}$ of free water per month. This area falls within the jurisdiction of the eThekwini Municipality which oversees the water supply and demand.

\section{METHODOLOGY}

A qualitative approach in the form of semi-structured interviews with main stakeholders used to gather data. This study aimed to gain insight into high water usage amongst residents in low-cost housing areas in the Waterloo Township. A total of eight participants were selected, two each from the water authority body (municipality), community-based organisations, academia and community representatives in government (councillors).

\section{DATA ANALYSIS}

This study used qualitative content analysis using operating coding to create categories to theme the data [20]. Three themes emerged from the study: (1) The viability of the current water management system, (2) Reducing water consumption; (3) How to change consumer behaviour on water conservation. All data analysis was performed with the aid of Nvivo. The quotes used are representative of the views of most, if not all, participants unless otherwise stated.

\section{RESULTS AND DISCUSSION}

\subsection{Theme 1: Sustainability of the current water management system}

Given the scarce and limited availability of water in SA, it is imperative that water be managed efficiently. However the long-term sustainability of the current water management system in SA is questionable when one considers the current water crisis recently faced in the city of Cape Town, and the eThekwini Municipality may well face similar challenges in the near future. Notably, some of the interviewees expressed a concern that the current water management under the eThekwini Municipality was not sustainable. This was evident in their assertion that the cost of water supply by the municipality does not measure to the revenue generated from it. This is reflected the statement made by Councillor 1: 
"The water management system is not sustainable as there is a huge gap between supply and demand. In fact the municipality is not taking concrete steps to mitigate loss which results in non-revenue water. It's $40 \%$ presently and that's a very high percentage considering we are a water scarce country".

Echoing similar sentiments, and from a financial context, the municipality participant 1 claimed that the city suffered a net loss of R400 million from water loss per year.

"looking at non-revenue figures of $40 \%$, that's a huge chunk. If you look at what we purchase water for, around R1 billion a year, that's a net loss of R400 million".

The net loss was blamed on water wastage and illegal tap connections. This is consistent with studies that show SA was losing over 1.5 billion cubic metres of water a year due to failing infrastructure, such as piping infrastructure which has outlived its lifespan and illegal connections. This resulted in a net loss of more than R7 billion worth of water lost annually [21], [22].

With regard to residents in the area being recipients of FBW, Municipality Representative 1 believed that the policy was no longer functional as householders were using more than the stipulated amounts of water as well as challenges monitoring water usage in the area due to theft of monitoring devices. As such, it was noted that even though there was high consumption of water in the area, there was not revenue being generated. This is consistent with a study which reported that despite progressive water policies, there still remained an inability by the government to effectively manage and control water resources in vulnerable communities [3]. Municipality Representative 1 further believed:

"If things don't change, we will be in crisis mode because we will either have to increase tariffs to those people who are paying and those people who are not paying will continue to abuse it".

The looming water crisis is expected to have implications on food security and health. Furthermore, if no suitable solutions are found, water scarcity will affect humanity [23]. In SA, a culture of non-payment of services and distrust in water authority bodies has contributed towards poor water behaviour [12].

However, some participants believed that even with the low storage levels currently experienced at major dams in the country, the current water management system was still sustainable. Academia Representative 1 cautioned that that dam levels were not indicative of consumption pattern, but rather storage patterns. He however, warned that the effects of climate change in the last decade has contributed significantly towards the scarcity of this resource.

"Dam levels are indicative of what we have in storage. It's not indicative of consumption patterns. The biggest user of water is agriculture sector. Domestic users sitting at a small percentage. In the last ten years one of the destructors on the planet is climate change. Climate change has significantly impacted on the world, fundamentally so on water".

One of the most important factors fuelling the water crisis is climate change with global warming affecting water systems, precipitation, and water availability [24]. Drawing from the above, it is reasonable to assume that more stringent measures should be in place to sustain and conserve water that goes beyond the dam level. It has further shown that among the emerging constraint to water sustainability is the high water-wastage and high consumption within the poor communities that account for the high non-revenue loss to the 
municipalities. Consequently, it was advocated by some of the participants that water waste and consumption should be minimized particularly within these communities.

\subsection{Theme 2: Reducing water consumption in low-cost housing communities}

This theme aimed at gaining participants' perspective on how to get water users in poorer areas to reduce their water consumption. Majority of the participants believed that education and communication played a significant role in informing residents on issues such as climate change, water scarcity and water behaviour. Participants also noted that community involvement and the use of existing structures such as councillors are some of the ways in which residents can reduce their water.

4.2.1 Subtheme 2.1: Reducing water consumption through education and communication Majority of the participants interviewed suggested that water consumption in the poorer communities can be reduced through education and communication. Consequently, community councillors called for more communication and education programs to educate individuals on ways to preserve water and calculate their consumption of water. For example, Councillor 2 challenged the municipality to take the initiative to educate people on water use and meter readings:

"The municipality must take the initiative to come here and educate people on water use, meter readings etc".

Furthermore, Councillor 2 lamented on an initial municipality project, "War on Leaks Project", aimed at educating members of the community in locating and fixing leaks on their property, which fell apart due to lack of feedback from the municipality. The afore-mentioned participant pointed to the fact that the project would have created employment within the community, as well as reduce water loss due from unreported leaks.

"As a Councillor in the area, I have been here 3 and half years, we only had communication from the municipality once. It was for the War on Leaks project where a feasibility study was conducted to seek out young people who can be employed to report leaks. However, that seems to have fallen away. There has been no feedback from the municipality since then. It would have been an excellent initiative as it would have created employment within the Waterloo community on one hand, and decrease water loss as a result of unreported leaks on the other hand".

The project was aimed at training 10,000 youth countrywide to locate and fix leaking pipes, however, it was halted due to budget constraints [25]. It was a short-lived vision that would not have only created employment within poor communities but also save water by locating and fixing leaks.

Another concern expressed by Councillor Two was that the communities only become aware of water consumption beyond the FBW limits when they received bills to settle the outstanding amounts of money for the extra water used.

"Unfortunately, people only become aware of their billing account when it has already become a major issue. There seems to be no concerted effort to manage water within the FBW limit. Communal pipes are a big problem here. There is no regular maintenance and leaks are not reported timeously". 
In fact, studies show that municipalities were struggling to manage FBW due to administrative and technical capabilities. Significantly, there was widespread theft and vandalism of monitoring devices on residential properties [10], [23].

Reiterating the call to educate communities on water conservation, Academic Water Representative 1 advocated for the education of school children to learn to appreciate the value of water. This could ultimately lead towards change in their behaviour.

"In terms of conserving water any other time, there is lack of communication. Education plays a role in all aspects of our lives. I believe if people are educated then there will be a change in behaviour. I also think it should start at school level. Educate the children. So that they will learn to appreciate the value of water".

It has been shown that people who are aware of their water situation was more likely to develop the appropriate water conservation behaviour [26]. The two municipality representatives were adamant that the communication department within the municipality was adept enough to assist consumers with their water consumption and billing queries. This was in the form of roadshows, public advertisements, educational tours, school campaigns aimed to educate the people on water conservation and water demand management.

However, despite the perceived drive to educate the people, one of the representatives from the municipality acknowledged that they faced a challenge related to the language barrier to effectively deliver their message to the people.

"One of the challenges we experience is the language barrier. Many people in rural areas, English is not the first language. I believe there needs to be a change in approach. Try to be more in line with the receiving audience. At the moment, the municipality has invested in pamphlets with lots of pictures so that grass root people can understand. People can learn to conserve water by changing their behaviour. They can find and fix leaks. One small drip per minute is almost 53 gallons of water wasted per year. Buy water-efficient appliances. Turn the water off before a vacation. Reuse old water and Insulate hot water pipes. Education plays a major role. And it should begin at school level".

In order to change people's behaviour towards water conservation it is important to equip them with the correct knowledge on how to save water. This effort is dependent on communication and language. Language barriers can hamper effective communication. However, speaking in a language that communities can relate to can encourage them to appreciate the environment as well as seek their commitment in changing their water use behaviour [26].

From the above statement, it is assumed that educating people is the key to changing their behaviour towards water conservation. Academic Water Representative 2 reiterated the sentiments of the above-mentioned authors:

"Educating members of the public and especially those from areas where there is high water consumption, is critical to making them understand issues such as water scarcity and climate change. This will create acceptance and make them more inclined towards water conservation efforts. Therefore, if people have a basic understanding of how water resources management and planning functions, they will begin to understand the associated economic and environmental benefits. As such, if consumers understood how water was priced and how much their used, this can contribute to healthier water behaviour". 
4.2.2 Subtheme 2.2: Reducing water consumption through community involvement

From the previous subtheme, communication and education were noted as important factors towards community involvement in water conservation. This notwithstanding, community representative 1 was emphatic that community involvement in any of water conservation strategy was a key factor. It was noted from this statement that communities needed to feel that they were part of the solution to the water problem. As a consequence, communities must be engaged at all levels in order to effectively conserve water.

"Community involvement is a key factor. Communities need to feel there are part of the solution. Therefore, they must be engaged at all levels. The only time we hear about water cuts or restrictions is when there is a drought. Then we are told to cut down on consumption. However, this is something that has to be communicated to the people all the time".

Community engagement and awareness programmes with municipalities may help to develop trust and more effective monitoring of service delivery such as water provision within the communities [27].

Academic water Representative 2 reaffirmed the need for a community participation model as a way to reducing water consumption but lamented that the community is often excluded from the solution process.

"the community is largely excluded from contributing to planning and decision making processes".

Whereas most of the interviewees agreed with the above statement, it must be noted that there are many water conservation initiatives in SA to create awareness around this dwindling resource [28]. However, the apathy is attributed to many citizens, particularly those in poor communities, who do not consider water conservation a priority [27]. In summary, the municipality can make greater effort to engage with communities their serve by involving them in decision making processes. In this way, communities feel they are contributing to a solution to a problem that affects them directly. Although majority of them believed education and communication were more plausible strategies, most believed that community participation was the key to changing consumer behaviour towards water use. Hence, the use of councillors to engage more often with the community was proposed by some of the interviewees.

\subsection{Theme 3: How to change consumer behaviour towards water consumption}

Water conservation is of utmost importance in a semi-arid country like SA given that it's in the middle of its worst drought in decades. As such, it is imperative that communities are aware on the need to conserve water. However, it was found that the attitude of the people living in the low-cost housing areas was a point for concern. Troublingly, payment for basic services like water and electricity in SA remains a challenge because there has been culture of non-payment [12]. Therefore, this undoubtedly calls for more innovative approaches to encourage a water saving culture and behavioural change. It is claimed that a change in behaviour will have a far more beneficial effect than draconian punitive economic actions. As such, all interviewees agreed that the best way to change people's behaviour was to make them feel part of the solution. Community Representative 2 stated:

"People who are receiving water bills are people who are using above the limit of free water provided by the municipality. That's where the municipality needs to 
intervene. Instead of sending bill with these amounts that people in the poor areas cannot afford, they should come and see what the problem is. That is why people are using so much water. Most of the time it is due to leaks and burst pipes".

Council representative 2 echoed the above sentiments that inhabitants of low-cost housing communities are left out of the problem-solving mechanisms when it comes to water conservation.

"Inhabitants don't feel like they are included in problem solving mechanisms when it comes to water conservation. Therefore, there is lack of interest on their part. This is reflected in their attitude towards water scarcity and the need to save water. They feel they are not important enough to be part of solutions. The lack of communication from the water authorities has contributed towards this behaviour".

Several studies indicate that the most obvious method of influencing consumption is pricing. However, it may not be influential in the context of a given amount of free water, and a culture of non-payment. This presents a challenge in many countries. Therefore, the effort to educate communities about water resource and water demand management issues is a mammoth task and over time will manifest itself more profoundly [27].

\section{CONCLUSION}

SA has one of the most progressive constitutions in the world enshrining water as a basic human right. However, while it recognises the right to safe clean water, putting it into practice is somewhat more challenging. The findings of this study highlighted the challenges surrounding interaction between individuals, communities and the municipality at the local level. By understanding the reasons which influence the demand for water in poor communities, their consciousness about their water situation and their willingness to use it more consciously, one can begin to develop the appropriate strategies for implementing rational use of water for this part of the population. This study has shown that the ability of the state to effectively manage water resources in low-income areas remains a huge challenge due to poor water conservation behaviour on the part of inhabitants. The study found that this was the result of poor engagement between the municipality and the community. Stronger efforts to involve the community by making them feel part of the solution through participatory and educational programs may be a way forward in helping them use water within the amounts stipulated in FBW.

\section{ACKNOWLEDGEMENTS}

The authors are highly grateful to the Durban University of Technology and the National Research Foundation of South Africa for their financial support in the form of an NRF-Free Standing, Innovation and Scarce Sills Doctoral Scholarship (107696) to carry out this work.

\section{REFERENCES}

[1] Rodina, L., Human right to water in Khayelitsha, South Africa: Lessons from a 'lived experiences' perspective. Geoforum, 72, pp. 58-66, 2016.

[2] Hellberg, S., Water for survival, water for pleasure: A biopolitical perspective on the social sustainability of the basic water agenda. Water Alternatives, 10(1), pp. 65, 2017.

[3] Ramírez, R.R., De Clercq, W. \& Jackson, M.N., Human Water Governance: A Social Innovation Model to Reduce the Inequalities of Water Services in South African Informal Settlements. New Paths of Entrepreneurship Development, Springer: Cham, pp. 231-255, 2019. 
[4] Hellberg, S., Water, life and politics: Exploring the contested case of eThekwini municipality through a governmentality lens. Geoforum, 56, pp. 226-236, 2014.

[5] Williams, N.J., Jaramillo, P., Taneja, J. \& Ustun, T.S., Enabling private sector investment in microgrid-based rural electrification in developing countries: A review. Renewable and Sustainable Energy Reviews, 52, pp. 1268-1281, 2015.

[6] Clark, C., Trans-jurisdictional water governance and implementing the human right to water in South Africa. Trans-Jurisdictional Water Law and Governance, eds J. Gray, C. Holley \& R. Rayfuse, Routledge, pp. 294-312, 2016.

[7] Szabo, A., The value of free water: Analyzing South Africa's free basic water policy. Econometrica, 83(5), pp. 1913-1961, 2015.

[8] Department of Water Affairs, South Africa, Strategic overview of water resources in SA. http://nepadwatercoe.org/wp-content/uploads/Strategic-Overview-of-the-WaterSector-in-South-Africa-2013.pdf. Accessed on: 1 May 2019.

[9] Jacobs-Mata, I.M., De Wet, B., Banoo, I., Meissner, R., De Lange, W.J. \& Strydom, W.F., Understanding residential water-use behaviour in urban South Africa. https://issuu.com/alive2green/docs/water_8. Accessed on: 26 May 2019.

[10] Maphela, B., Critical assessment of South Africa's water policy. PhD thesis, University of Johannesburg, p. 34, 2015.

[11] Ojo, T.A., Water access challenges and coping strategies in informal settlements: The case Ofiscor settlement in Pretoria West. PhD thesis, UNISA, 2018.

[12] Nkosi, J.F., Low cost housing in Southern Africa and the quality compared with the post government housing for the poor.

https://repository.up.ac.za/bitstream/handle/2263/11555/Nkosi_Low(2009).pdf?sequ ence $=1$. Accessed on: 24 Jun 2019.

[13] Gaddis, E., et al., Freshwater Policy, 6, pp. 399-424, 2019.

[14] Rusca, M. \& Schwartz, K., The paradox of cost recovery in heterogeneous municipal water supply systems: Ensuring inclusiveness or exacerbating inequalities? Habitat International, 73, pp. 101-108, 2018.

[15] Chatterji, M., Arlosoroff, S. \& Guha, G., Conflict Management of Water Resources, Routledge: Collana, 2017.

[16] Bond, P., 10 South African commoning of medicines and water beyond human rights rhetoric. Varieties of Alternative Economic Systems: Practical Utopias for an Age of Global Crisis and Austerity, eds R. Westra, R. Albritton \& S. Jeong, Taylor \& Francis, pp. 157, 2017.

[17] Dell'Angelo, J., D’Odorico, P. \& Rulli, M.C., Threats to sustainable development posed by land and water grabbing. Current Opinion in Environmental Sustainability, 26, pp. 120-128, 2017.

[18] Sinclair-Smith, K. \& Winter, K., Water demand management in Cape Town: Managing water security in a changing climate. Mainstreaming Climate Change in Urban Development: Lessons from Cape Town, eds D. Scott, H. Davies \& M. New, JUTA, 2019.

[19] Carley, M. \& Christie, I., Managing Sustainable Development, Routledge, 2017.

[20] Saldaña, J., The Coding Manual for Qualitative Researchers, Sage, 2015.

[21] Mavundla, N.B., The effectiveness of local government in water usage in Ezakheni township. PhD thesis, University of the Free State, p. 39, 2016.

[22] Ramulongo, L., Nethengwe, N.S. \& Musyoki, A. The nature of urban household water demand and consumption in Makhado local municipality: A case study of Makhado Newtown. Procedia Environmental Sciences, 37, pp. 182-194, 2017. 
[23] Larsen, T.A., Hoffmann, S., Lüthi, C., Truffer, B. \& Maurer, M., Emerging solutions to the water challenges of an urbanizing world. Science, 352(6288), pp. 928-933, 2016.

[24] Barlow, M. \& Clarke, T., Blue Gold: The Battle against Corporate Theft of the World's Water, Routledge, 2017.

[25] Infrastructure News, Department of Water to rethink war on leaks programme. https://infrastructurenews.co.za/2019/02/14/department-of-water-to-rethink-war-onleaks-programme/. Accessed on: 12 Jun. 2019.

[26] Onyenankeya, K. \& Salawu, A., Negotiating water conservation communication through indigenous media. Communitas, 23, pp. 178-193, 2018.

[27] Hove, J. et al., 'Water is life': Developing community participation for clean water in rural South Africa. BMJ Global Health, 4(3), e001377, 2019.

[28] Knüppe, K. \& Meissner, R., Drivers and barriers towards sustainable water and land management in the Olifants-Doorn Water Management Area, South Africa. Environmental Development, 20, pp. 3-14, 2016. 